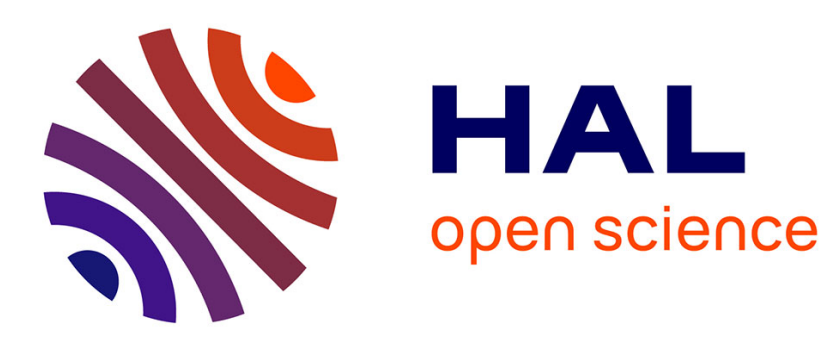

\title{
Nonlinear adaptive sliding mode control of a powertrain supplying fuel cell hybrid vehicle
}

\author{
Mohamed Djameleddine Bougrine, Atallah Benalia, Mohamed Benbouzid
}

\section{To cite this version:}

Mohamed Djameleddine Bougrine, Atallah Benalia, Mohamed Benbouzid. Nonlinear adaptive sliding mode control of a powertrain supplying fuel cell hybrid vehicle. IEEE ICSC 2013, Oct 2013, Algiers, Algeria. pp.1-6. hal-01023556

\section{HAL Id: hal-01023556 https://hal.science/hal-01023556}

Submitted on 14 Jul 2014

HAL is a multi-disciplinary open access archive for the deposit and dissemination of scientific research documents, whether they are published or not. The documents may come from teaching and research institutions in France or abroad, or from public or private research centers.
L'archive ouverte pluridisciplinaire HAL, est destinée au dépôt et à la diffusion de documents scientifiques de niveau recherche, publiés ou non, émanant des établissements d'enseignement et de recherche français ou étrangers, des laboratoires publics ou privés. 


\section{Nonlinear adaptive sliding mode control of a powertrain supplying Fuel Cell Hybrid Vehicle}

\author{
M. D. Bougrine, A. Benalia \\ LACoSERE Laboratory, University of Laghouat \\ Laghouat, ALGERIA
}

\author{
M. Benbouzid \\ University of Brest, EA 4325 LBMS \\ Brest, FRANCE
}

\begin{abstract}
This paper presents an adaptive sliding mode based switching scheme for controlling DC-DC hybrid powertrain for propulsion of a Fuel Cell / Supercapacitor hybrid vehicle. After modeling the powertrain, a new approach to determine a nonlinear sliding surface ensuring stability of the DC/DC Boost converter is discussed. This was achieved without introducing the equivalent control aspect after transforming the instantaneous model of the Boost in a suitable form. The presented technique is also applied for trajectories tracking in the entire powertrain, which includes a dc/dc Boost converter associated to Fuel Cell stack and another Bidirectionnel dc/dc converter associated to the supercapacitor bank, which are both working in parallel to provide electricity propelling the vehicle. The control scheme is tested with driving cycle example through simulation.
\end{abstract}

Index Terms- Sliding mode control, Fuel cell vehicle, hybrid powertrain, dc/dc converter.

\section{INTRODUCTION}

The transport domain remains among the most projecting areas that would benefit from hydrogen. The vehicles considered are recognized with Fuel Cell Vehicles (FCV). Although this fuel cell, which serves to produce electricity by oxidizing hydrogen, provides a durable energy source for the vehicle, this one misses providing a fast and reversible source for managing load current peaks and recuperation of energy fluxes resulting from braking. This leads to the necessary use of reversible secondary source as a battery or supercapacitor working in parallel with the fuel cell block.

As each vehicle with a hybrid propulsion source, the fuel cell hybrid vehicle gives rise to an additional degree of freedom for its traction. This requires defining an energy management law in order to determine in each time interval, the current distribution between different sources to meet correctly its propulsion [1]. The goal is generally to minimize the consumption of the Hydrogen during the tracking cycle with respect to the constraints related to state of charge limits of the secondary source, and the response time limit of the Fuel Cell. [2],[3]. In this context, the regulation problem of switched power converters used on hybrid electric vehicles or more generally on any hybrid power supply has received remarkable attention in recent years. However, in [4] interleaved Boost topology was presented with PID based control scheme to guarantee the trajectory tracking in the $\mathrm{DC} / \mathrm{DC}$ powertrain. Other control schemes as sliding mode and flatness control are also tested [5],[6]. The surface used in sliding mode was linear, and the design is done thanks to the linearized model of the Boost, what practically affects the robustness of the control. Moreover, these techniques are generally averaged model based, which requires passing through PWM to convert continuous data of duty cycles generated by the controller to a switching values.

The Boolean character of switching systems in power electronic makes sliding mode better suited compared to conventional control techniques with continuous algebra (PI, PID, linear / nonlinear state feedback) [5]. Except of under-actuated systems, the sliding mode allows a finite time convergence to the equilibrium point through a surface. Inside that surface, which is a manifold with lower order than the system, the trajectory earns more robustness compared if trajectory evolution was in the complete state space [7].

The development of this new sliding mode based technique in this paper, tailored towards dc-dc converters, is motivated by the search for high performance controller. Section II begins with modeling a simple dc/dc Boost and $\mathrm{dc} / \mathrm{dc}$ Bidirectional converter and finishes with illustrating the instantaneous model of the entire powertrain. In section III, a control design for the boost connected to the FC using sliding mode and its stability analysis are presented, the section is completed with adaption of surface's coefficients for best performance, followed in section IV bye simulation results obtained for the $\mathrm{dc} / \mathrm{dc}$ Boost connected to the fuel cell and then, the entire powertrain propelling the vehicle.

\section{DESIGN AND MODELING OF THE VEHICLE POWERTRAIN}

As shown in Figure I, the conversion chain is composed of two dc/dc blocks, a boost converter associated to the fuel cell stack used to impose a fixed voltage on the dc output bus. Another bidirectional $\mathrm{dc} / \mathrm{dc}$ converter is associated to the reversible source. It operates in Boost mode when we provide current to the motor and in Buck mode when current resulting from braking and/or from the fuel cell is received to the stock. We have to select that in similar hybrid powertrains, one of converter circuits is controlled in output voltage to impose a specific value on the dc bus. The 
other converter(s) is (are) controlled in current mode, that wants to say the input current and consequently the output current on each converter current controlled are forced to track a specified trajectory, which is the result of a power management algorithm. The current circulating in the voltage-controlled converter is inevitably imposed by the architecture. Let us say, it is equal to the difference between the load current and the sum of other output currents.

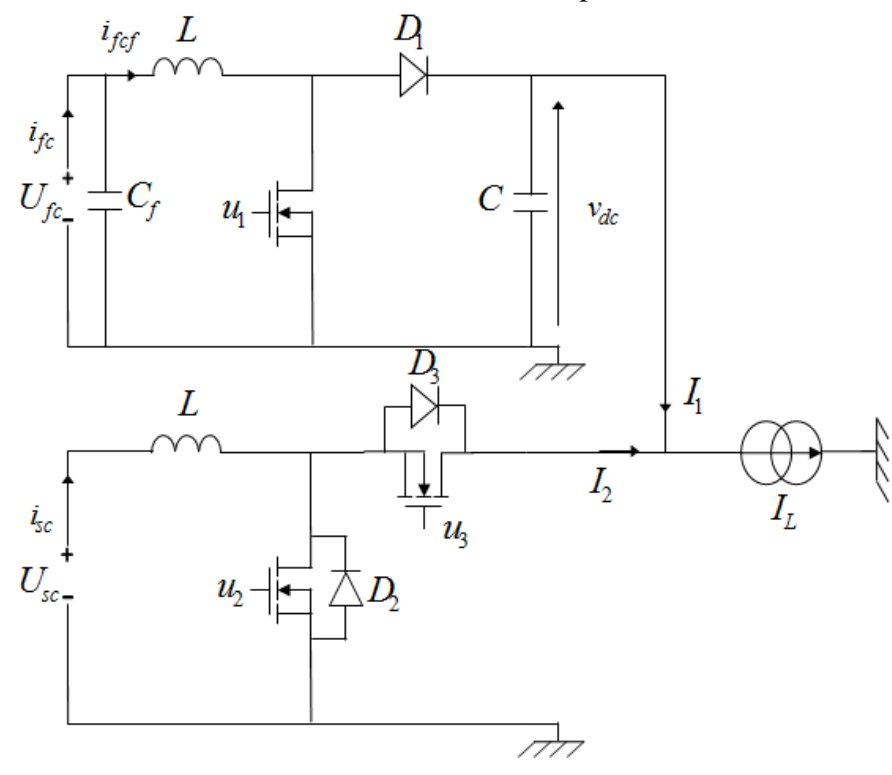

Fig. I. FC/ Supercapacitor hybrid powertrain

In control engineering, we can consider three manners to present a state space model reflecting the control/states relationship in power converter circuits: (i) averaged continuous models (ii) instantaneous models (generally discontinuous) and (iii) hybrid models (continuity by modes). Some are compatible with some control techniques and not with others. Therefore, the choice of the control technique depends strongly on the choice of modeling method.

In the recent work, we present a nonlinear sliding mode based control of the presented powertrain. Regardless of hybrid modeling, sliding mode control allows the use of the exact discontinuous model, which is not the case of many conventional techniques. The advantage is that Pulse Width Modulation (PWM) is not needed, but instead, the instantaneous switching states are directly deducted from state measurements. In the present paper, we adopt the exact discontinuous model. Thus, high frequency dynamics are not neglected.

\section{A. Modeling the DC/DC Boost connected to the FC}

A system such as a boost converter can be described as a nonlinear discontinuous system. The form bellow represents the instantaneous state vector of the boost when the diode $D_{1}$ is always active.

$$
\begin{aligned}
& \dot{x}_{1}=\frac{1}{L}\left(U_{f_{c}}-\bar{u}_{1} x_{2}\right) \\
& \dot{x}_{2}=\frac{1}{C}\left(\bar{u}_{1} x_{1}-I_{1}\right)
\end{aligned}
$$

With $x=\left[\begin{array}{ll}i_{f c f} & v_{d c}\end{array}\right]^{T} \in \mathfrak{R}^{2}$ is the state vector; $u_{1} \in\{0,1\}$ is a Boolean switching variable and $\bullet:\{0,1\} \rightarrow\{0,1\}$ is the Not function.

Alike, the bidirectional DC/DC associated to the supercapacitor pack is modeled. Nevertheless, depending on the sign of $i_{s c}$, the converter operates Boost or Buck. For each of both modes we associate a corresponding model. In this case, the dynamic of $x_{2}$ could be assumed constant when we want to do a separated control scheme.

$$
\dot{x}_{3}=\left\{\begin{array}{lll}
\frac{1}{L}\left(U_{s c}-\bar{u}_{2} x_{2}\right) & \text { if } & x_{3}>0 \\
\frac{1}{L}\left(U_{s c}-u_{3} x_{2}\right) & \text { if } & x_{3}<0
\end{array}\right.
$$

With $x_{3}=i_{s c} \in \mathfrak{R}$ is the state vector; $u_{2}$ and $u_{3}$ have the same nature as $u_{1}$.

\section{B. Modeling the entire $D C / D C$ powertrain}

Both $\mathrm{dc} / \mathrm{dc}$ converters are merged in one compact state model representing the control/states relationship of the entire powertrain. The sign of $x_{3}$ indicates the operating mode of the Bidirectional dc/dc converter, and consequently the entire powertrain. Hence, the hybrid modeling concept is also introduced. To do, we just apply the Kirchoff current law at the output node to appear $I_{L}$ instead $I_{1}$.

$$
I_{1}=I_{L}-I_{2} \quad \text { With } I_{2}=\left\{\begin{array}{lll}
\bar{u}_{2} x_{3} & \text { if } & x_{3}>0 \\
u_{3} x_{3} & \text { if } & x_{3}<0
\end{array}\right.
$$

Finally, we are about to show the total powertrain state model.

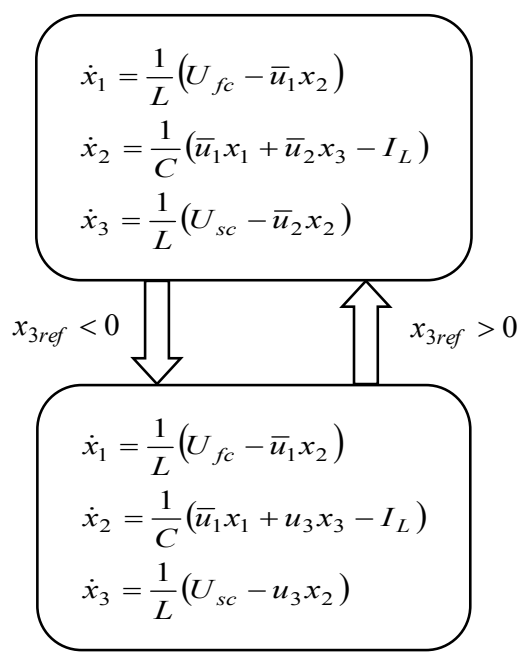

Fig. 2. Instantaneous state model of the hybrid powertrain 


\section{CONTROL DESIGN OF THE BOOST CONNECTED TO THE}

FC

The restriction of the input control in the Boolean space prevents the use of a continuous feedback function. We can find for example a control with the form:

$u_{1}=$ heaviside $(\sigma(x))$ with: Heaviside: $\mathfrak{R} \rightarrow\{0,1\}$ is a Boolean defined multivalued function.

$\forall x \in \Re$, heaviside $(x) \in\left\{\begin{array}{lll}0 & \text { if } & x<0 \\ 1 & \text { if } & x>0 \\ \{0,1\} & \text { if } & x=0\end{array}\right.$

We call sliding surface, the manifold defined in the phase space as:

$$
S:\left\{x \in \mathfrak{R}^{2} / \sigma(x)=0\right\}
$$

The Heaviside function means that we switch between 0 and 1 depending on the sign of $\sigma(x)$. As it is known, the major difficulty in that type of control is the choice of a surface that ensures local stability of the origin. Where the minimal required locality is stated by all possible initial states.

In this section, we show a simple approach that permits to obtain a nonlinear sliding surface that leads the system to the origin. The choice is made in two steps: (i) Find a local diffeomorphism transforming the system in a suitable form (the diffeomorphism is generally nonlinear); and (ii) synthesize a linear surface in the new frame. Here, we will see how the demonstration of the origin stability is less complicated in the new frame, and this, without introducing the equivalent control concept.

\section{A. Transforming the state model in a suitable form}

The objective is to find a local diffeomorphism $\Phi(x)$ such that Eq (1) has the following form:

$$
\begin{aligned}
& \dot{z}_{1}=z_{2} \\
& \dot{z}_{2}=\varphi\left(z_{1}, z_{2}\right)+\zeta\left(z_{1}, z_{2}\right) u_{1}
\end{aligned}
$$

Let us consider $z_{1}=\Phi_{1}(x)$, then we can write:

$$
\dot{z}_{1}=\frac{\partial \Phi_{1}}{\partial x_{1}} \dot{x}_{1}+\frac{\partial \Phi_{1}}{\partial x_{2}} \dot{x}_{2}
$$

By replacing $\dot{x}_{1}$ and $\dot{x}_{2}$ from (1) we obtain:

$$
\dot{z}_{1}=\frac{U_{f c}}{L} \frac{\partial \Phi_{1}}{\partial x_{1}}-\frac{I_{1}}{C} \frac{\partial \Phi_{1}}{\partial x_{2}}+\bar{u}_{1}\left(\frac{1}{C} \frac{\partial \Phi_{1}}{\partial x_{2}} x_{1}-\frac{1}{L} \frac{\partial \Phi_{1}}{\partial x_{1}} x_{2}\right)
$$

To get rid of $u_{1}$ from the previous equation we just make an appropriate choice of $\Phi_{1}$. Then, $\Phi_{1}$ should check the following equation:

$$
\frac{1}{C} \frac{\partial \Phi_{1}}{\partial x_{2}} x_{1}=\frac{1}{L} \frac{\partial \Phi_{1}}{\partial x_{1}} x_{2}
$$

Then, the first part of the diffeomorphism is given as follows:

$$
\Phi_{1}\left(x_{1}, x_{2}\right)=z_{1}=L x_{1}^{2}+C x_{2}^{2}
$$

From (3) we have:

$$
\dot{z}_{1}=2 U_{f c} x_{1}-2 I_{1} x_{2}=\Phi_{2}\left(x_{1}, x_{2}\right)=z_{2}
$$

We just obtain $\dot{z}_{2}$ by derivation of (11), the system is written in the new frame as:

$$
\begin{aligned}
& \dot{z}_{1}=z_{2} \\
& \dot{z}_{2}=\frac{2 U_{f_{c}}^{2}}{L}+\frac{2 I_{1}^{2}}{C}-\bar{u}_{1}\left(\frac{2 U_{f c}}{L} x_{2}+\frac{2 I_{1}}{C} x_{1}\right)
\end{aligned}
$$

\section{B. Surface design and stability analysis}

Let us consider the following linear surface $\sigma_{1}$ :

With;

$$
\sigma_{1}=k_{1} \delta_{1}+k_{2} \delta_{2}
$$

$$
\delta_{1}=z_{1}-z_{1 r e f} \text { And } \delta_{2}=z_{2}-z_{2 r e f}=z_{2}
$$

Since the surface contains the origin, we show two sufficient conditions for the stability of the origin. (i) The sliding surface contains a locally finite time stable subset containing the origin; and (ii) the origin is stable in that subset.

In [8], [9] a sufficient condition inspired from Lyapunov theorem of stability, which allows concluding on the asymptotic stability of the surface. This one becomes sufficient for the finite time stability, if the vector field function is nonlipschitzian on the surface, which is indeed the case in sliding mode control since the feedback function is discontinuous on the surface.

If we consider a Lyapunov function $V_{l 1}=\sigma_{1}^{2}$ of the system (12), that is null on the surface $\mathrm{S}$ and strictly positive outside.

$\mathrm{S}$ is asymptotically stable if:

$$
\exists U \subset \mathfrak{R}^{2} / S: \dot{V}_{l 1}=\sigma_{1} \dot{\sigma}_{1}<0 \quad \forall \delta \in U
$$

This condition means that all points in $U$ converge asymptotically to the surface, which is not sufficient to the existence of sliding mode. In [10], [11] a stronger and sufficient condition ensuring that all points in $U$ reach in finite time the surface.

Therefore, with the same Lyapunov function $V_{l 1}, \mathrm{~S}$ is finite time stable if:

$$
\exists U \subset \mathfrak{R}^{2} / S, \exists \eta>0: \operatorname{sgn}\left(\sigma_{1}\right) \dot{\sigma}_{1}<-\eta \quad \forall \delta \in U
$$

So; 
$\operatorname{sgn}\left(\sigma_{1}\right) \dot{\sigma}_{1}=\left\{\begin{array}{lll}-k_{1} \delta_{2}-k_{2}\left(\frac{2 U_{f c}}{L}\left(1-x_{2}\right)+\frac{2 I_{1}}{C}\left(1-x_{1}\right)\right) & \text { if } & \sigma_{1}<0 \\ k_{1} \delta_{2}+k_{2}\left(\frac{2 U_{f c}^{2}}{L}+\frac{2 I_{1}^{2}}{C}\right) & \text { if } & \sigma_{1}>0\end{array}\right.$

Which is verified in a neighborhood of the origin by simple choice of $k_{1}$ and $k_{2}$ two negative real numbers. Knowing that the condition above is not necessary, the stability of the surface is verified geometrically in the phase space. Fig .3 illustrates some trajectories of the boost with different initial states. The surface colored in blue seems stable for all possible initial states. The dotted area presents the region where (14) is not verified. However, in that region we have $\operatorname{sgn}\left(\sigma_{1}\right) \dot{\sigma}_{1}>0$, nonetheless, the trajectories entering the dotted region leave it to another one wherein (14) is verified.

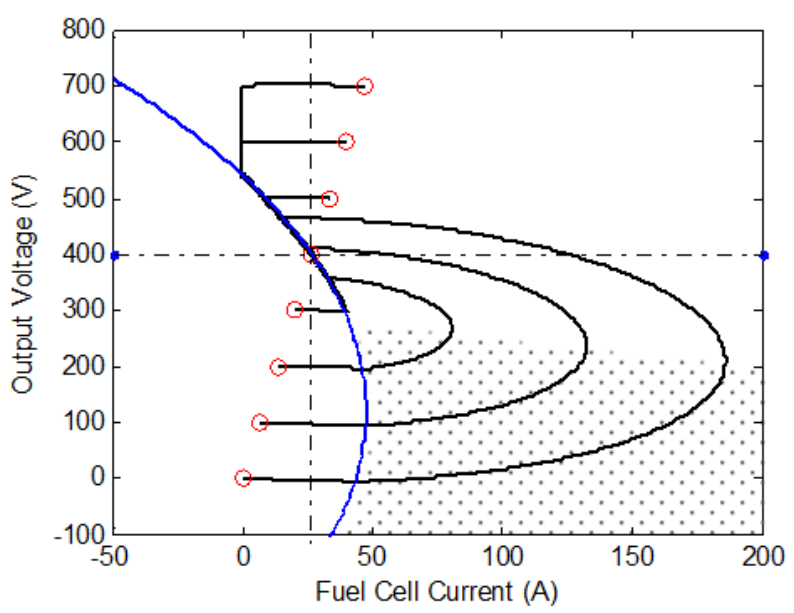

Fig. 3. Trajectories of sliding mode controlled Boost for different initial states.

The second condition for the stability of the origin by sliding mode is also verified. In the literature, we were accustomed to evaluate the equivalent control, the averaged value of $u_{1}$ which acts on the surface to make it invariant. However, this task is no longer necessary after transforming the system by the diffeomorphism $\Phi$, which is all its significance. If the surface is locally finite time stable, it implies that we reach it after a certain time called "settling time" [11]. Then, we can write:

$$
\sigma_{1}=k_{1} \delta_{1}+k_{2} \delta_{2}=0
$$

From (15) and (12) we obtain:

$$
\delta_{2}=\dot{\delta}_{1}=-\frac{k_{1}}{k_{2}} \delta_{1}
$$

Showing that the origin is exponentially stable inside the surface $\mathrm{S}$ with a dynamic sensitive to $k_{1}$ and $k_{2}$. In practice, the origin is not exponentially stable with sliding mode but rather there are an exponential convergence to a limit cycle around the origin. This is because the existence of a dead time between measurement and switch control, which lets the Heaviside function having hysteresis effect.

The choice of $k_{1}$ and $k_{2}$ is not very delicate task since we require that the two constants are just negative to ensure an exponentially stable origin in the surface. The dynamic of the system into the surface is governed by the ratio between $k_{1}$ and $k_{2}$. Therefore, it is common to choose it very high, but under that choice, the transient regime is affected, and a high absolute value of $k_{1}$ versus $k_{2}$ results in an important peaks of current and voltage. For what, we fixe $k_{2}$ to constant value $\left(\left|k_{2}\right|=1\right)$ and $k_{1}$ is controlled regarding the distance from the origin. Indeed, $k_{1}$ starts relatively small in absolute value, and becomes continually greater when the state is closer to the origin. Fig .5 shows the adaptation of $k_{1}$ regarding the distance from the origin measured in the square of Euclidian norm $\left\|x-x_{\text {ref }}\right\|_{2}^{2}$ what makes the surface adaptive.

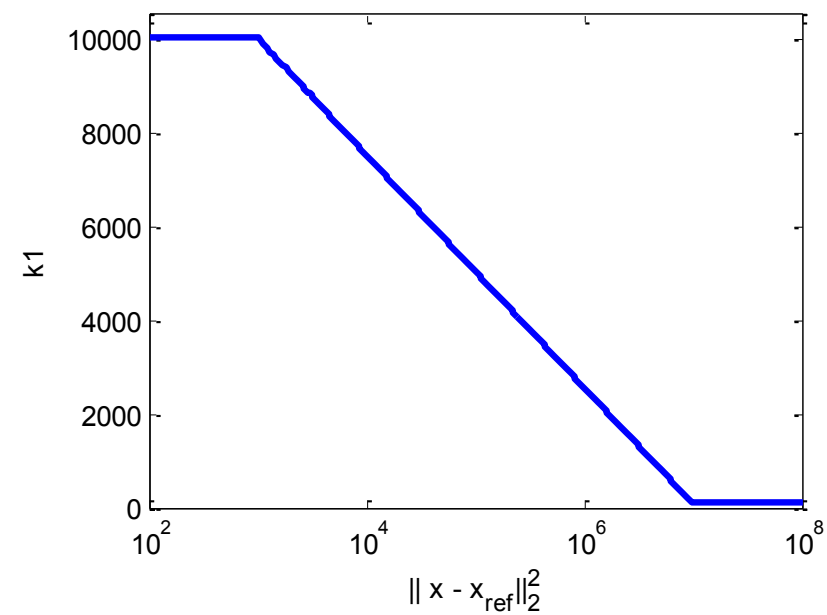

Fig. 4. Adaption of the coefficient $k_{1}$ according to Euclidian distance

\section{Simulation RESUlts}

\section{A. The Boost connected to the FC}

Fig 4 shows the I-V characteristics in the operating range of the Fuel Cell under standard conditions of temperature and pressure. (See [12] for more detail). 


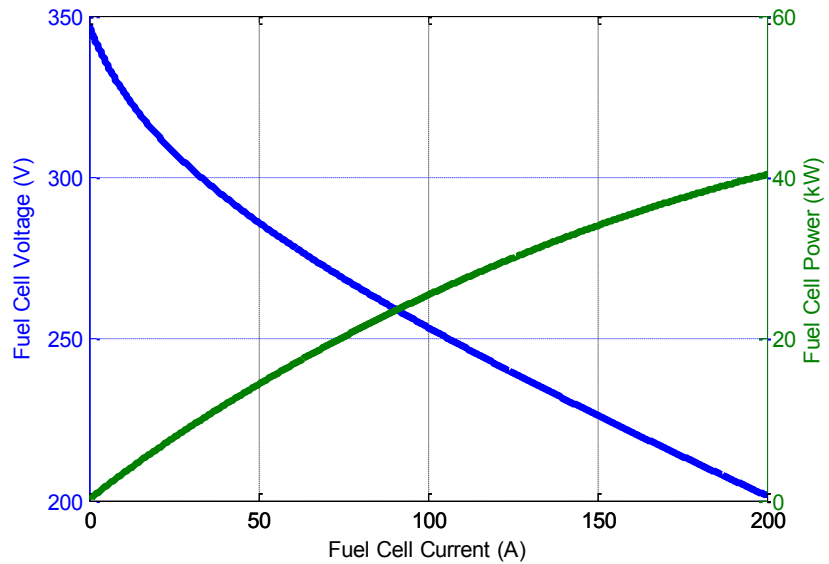

Fig. 5. I-V characteristics of the Fuel Cell used for the simulation.

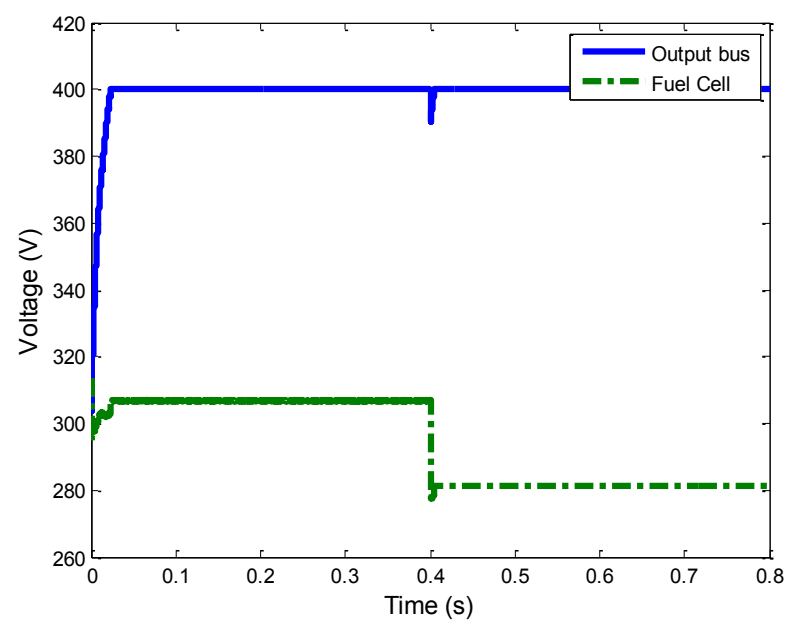

Fig. 6. Output Bus and Fuel Cell voltages of the controlled boost with load change at $t=0.4 \mathrm{~s}$ (See Fig. 7)

\section{B. Control of the entire powertrain}

In this sub-section, we are about to show all state feedbacks. The bidirectional converter is also controlled by sliding mode, so the difference we show compared to the converter associated to the Fuel Cell block is the no consideration of the output voltage in the surface. Respecting the singular perturbation theory in power systems [14], we just interest to the fast dynamic, which is the supercapacitor current. Thus, the choice of the surfaces is intuitive and the stability of reference trajectory is obvious.

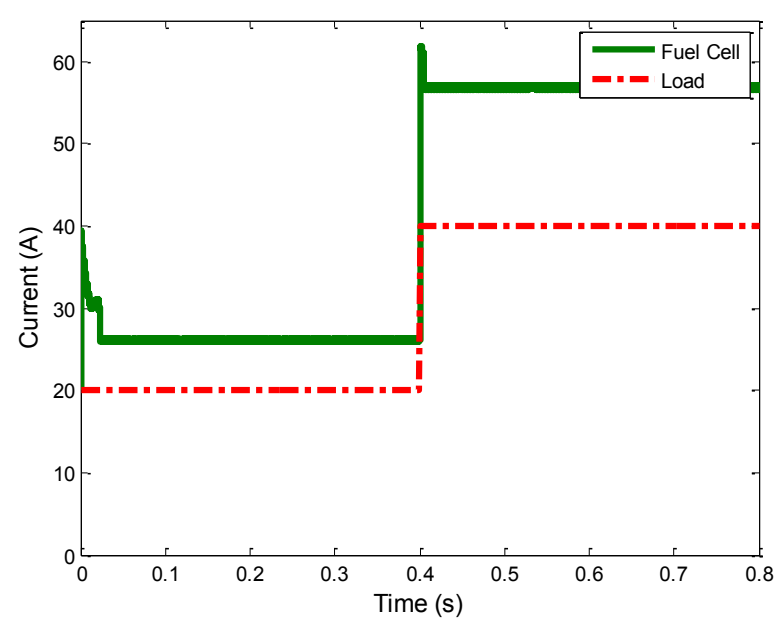

Fig. 7. Load and Fuel Cell currents of the controlled Boost (Load changes from 20 to $40 \mathrm{~A}$ at $\mathrm{t}=0.4 \mathrm{~s}$ )

$$
\begin{aligned}
& \sigma_{1}=k_{1}\left(z_{1}-z_{1 r e f}\right)+k_{2}\left(z_{2}-z_{2 r e f}\right) \\
& \sigma_{2}=-x_{3}+x_{3 r e f} \\
& \sigma_{3}=x_{3}-x_{3 r e f}
\end{aligned}
$$

With;

$$
\begin{aligned}
& z_{1 r e f}=L x_{1 r e f}{ }^{2}+C x_{2 r e f}^{2} \\
& z_{2 r e f}=2 U_{f c} x_{1 r e f}-2 I_{L} x_{2 r e f}=0 \\
& x_{1 \text { ref }}=\frac{I_{L} x_{2 r e f}-U_{s c} I_{s c}}{U_{f c}} \\
& x_{2 \text { ref }}=400 \mathrm{~V} \\
& x_{3 \text { ref }}=I_{\text {scref }}
\end{aligned}
$$

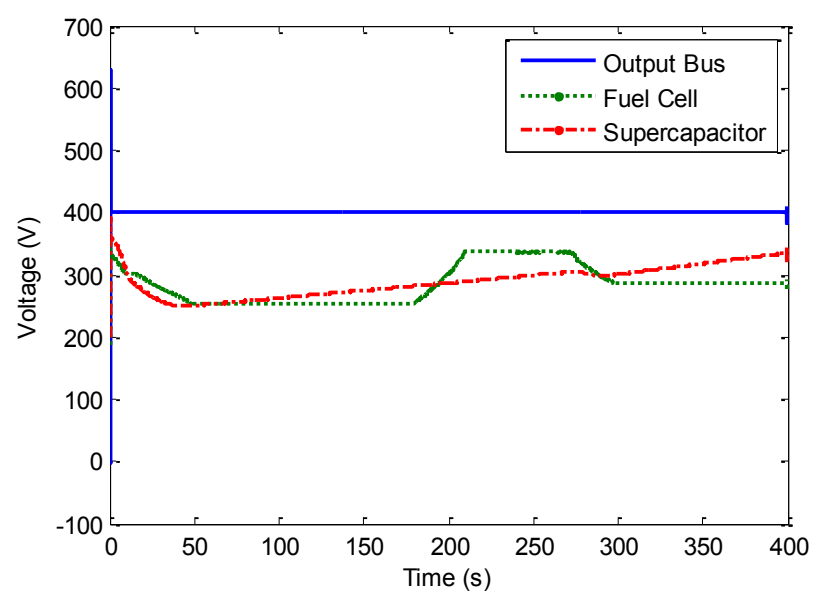

Fig. 9. Different voltages in the powertrain simulated with power cycle example (See Fig. 10.) 


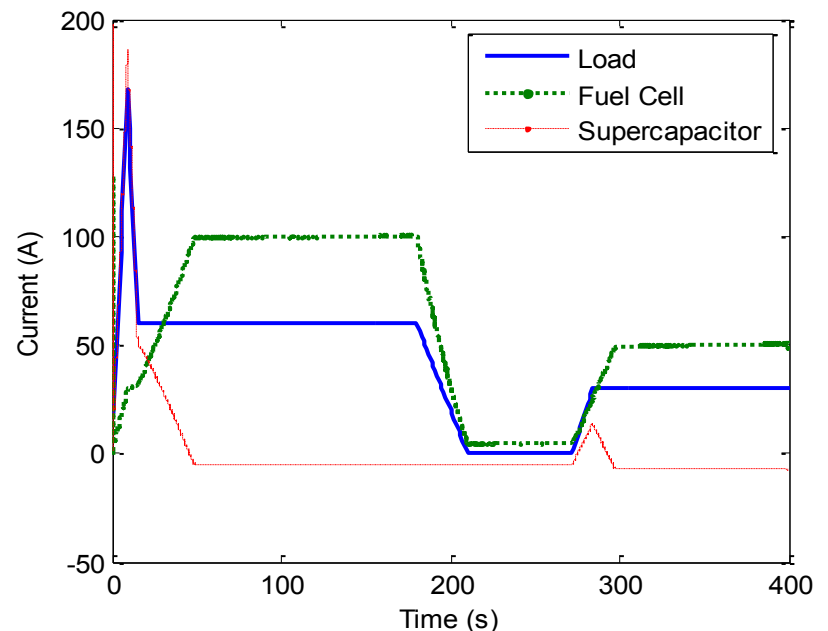

Fig. 10. Different currents in the powertrain simulated with power cycle example (load cycle in blue)

\section{CONCLUSION}

In this paper, was presented a new adaptive nonlinear sliding mode approach, applied to powertrain for hybrid Fuel Cell vehicle. The surface was chosen linear in another nonlinear frame obtained by application of a diffeomorphism to the system. The goal was to master the dynamic of the Boost on the surface without introducing the equivalent control concept. By simulation of the Boost and the entire powertrain of an FCV in Matlab/SIMULINK environment, results was very satisfactory with respect of abrupt load variation.

The next step in this research project is the implementation and experimental validation in the laboratory of the proposed strategy and control laws in reduced voltage test station,. It is also important to emphasize that a complete hybrid autonomous system is under study, adding another sources, with the possibility of the generation of the control laws by introducing the concept of flatness.

\section{REFERENCES}

[1] A. Lachichi and N. Schofield, "Comparison of DC-DC Converter Interfaces for Fuel Cells in Electric Vehicle Applications", Vehicle Power and Propulsion Conference, 2006, Windsor , 6-8 Sept, IEEE VPPC 2006

[2] Chan-chiao Lin, Huei Peng, J.W.Grizzle, "Power management strategy for a parallel hybrid electric truck", proceeding of the 2002 Mediterranean control Conference, Lisbon, Portugal,July 2002.

[3] B.A. Kalan, H.C.Lovatt, M. Brothers, V.Buriak "System design and development of hybrid electric vehicles" IEEE, Power Electronics Specialists Conference, (ISBN: 0-7803-7262-X), vol. 2, pp. 768- 772, Australia 2002.

[4] S. Karthik Kumaran, Dr KR Santha,"DSP Control of DC/DC Boost Converter for Fuel", IEEE- International Conference On Advances In Engineering, Science And Management (ICAESM -2012) March 30, 31,2012

[5] Gokasan, M, "Sliding mode based powertrain control for efficiency improvement in series hybrid-electric vehicles", IEEE Transactions On Power Electronics, Vol. 21, No. 3, May 2006

[6] Benedikt Alt, Felix Antritter and Ferdinand Svaricek Member, IEEE, "Flatness based Control for Electric and Hybrid Electric Vehicle Drivetrains", 2012 20th Mediterranean Conference on Control \& Automation (MED) Barcelona, Spain, July 3-6, 2012

[7] Hebertt Sira-Ramirez and Miguel Rios-Bolivar, "Sliding Mode Control of dc-to-dc Power Converters via Extended Linearization" IEEE Transactions on Circuits and Systems-i: Fundamental Theory and Applications, vol. 41, No. 10, October 1994.

[8] Buhler.H "Réglage par mode de glissement" Complément au traité d'électricité, presse

[9] H. Maker, H. Gualous, R. Outbib "Sliding Mode Control with Integral of Boost Converter by Microcontroller" IEEE CCA/CACSD/ISIC, Munchen, Germany 2006.

[10] W. Perruquetti , "J. P. Barbot Sliding mode control in engineering". Marcel Dekker Hardcover, 2002.

[11] S. P. Bhat, D. S. Bernstein. Finite Time Stability of Continuous Autonomous Systems. SIAM J. Control Optim., vol. 38, no. 3, 2000.

[12] Hattab Maker, " Optimisation et gestion d'énergie pour un système hybride : association Pile à Combustible et Supercondensateurs ", $\mathrm{PhD}$ thesis, Université de Franche-Comté, $\mathrm{N}^{\circ}$ ordre : 96, 2008. 